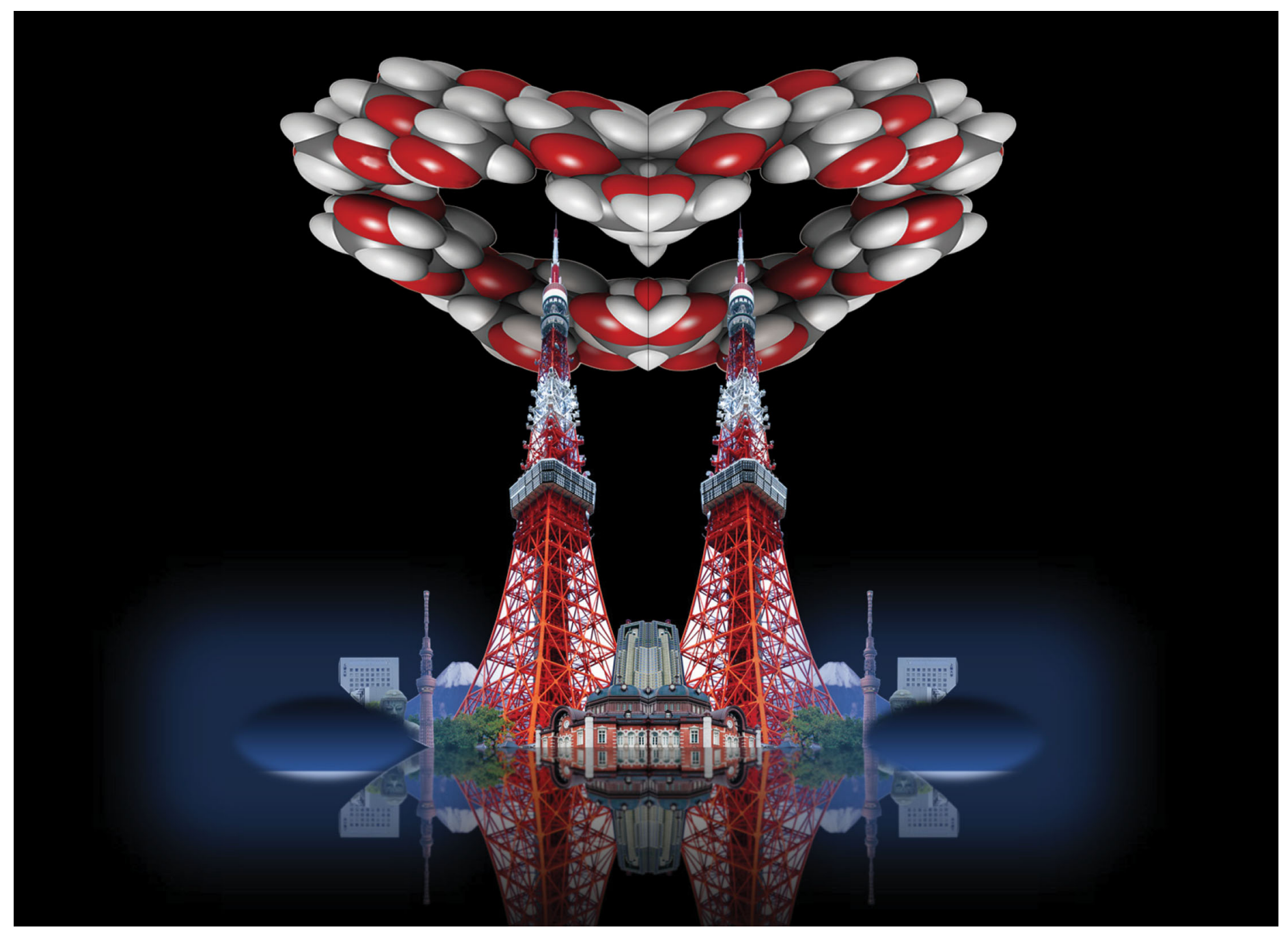

Showcasing research from the analytical chemistry group of Professor Takashi Hayashita at Department of Materials and Life Sciences, Faculty of Science and Technology, Sophia University, Tokyo, Japan.

Structural effects of ditopic azoprobe-cyclodextrin complexes on the selectivity of guest-induced supramolecular chirality

The selectivities of guest-induced supramolecular chirality for cations and anions were dramatically altered by a slight change in the spacer length of (15C5-Azo-n-dpa) ${ }_{2}-\gamma$-cyclodextrin complexes in water.
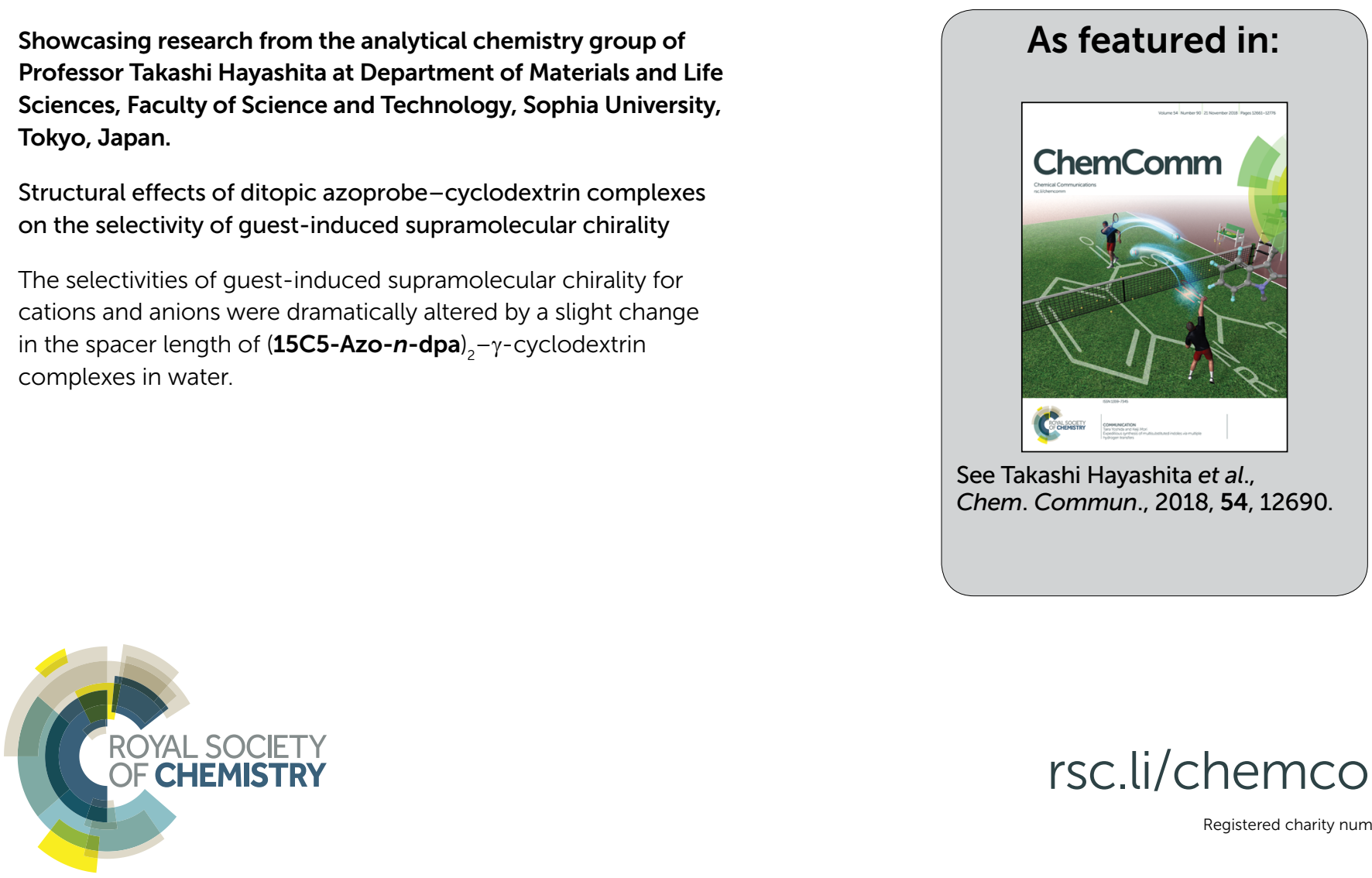
Check for updates

Cite this: Chem. Commun., 2018, 54, 12690

Received 20th March 2018, Accepted 16th June 2018

DOI: $10.1039 / c 8 c c 02242 a$

rsc.li/chemcomm

\section{Structural effects of ditopic azoprobe- cyclodextrin complexes on the selectivity of guest-induced supramolecular chirality $\dagger$}

\author{
Shoji Fujiwara, (DD ${ }^{a b}$ Kentaro Nonaka, ${ }^{b}$ Mai Yamaguchi, ${ }^{b}$ Takeshi Hashimoto (D) ${ }^{b}$ and \\ Takashi Hayashita iD *b
}

\begin{abstract}
Benzo-15-crown-5 and dipicolylamine are contained as the binding sites in a ditopic azoprobe (15C5-Azo- $n$-dpa). However, the selectivities of guest-induced supramolecular chirality for cations and anions were dramatically altered by a slight change in the spacer length of $(15 C 5-A z o-n-d p a)_{2}-\gamma$-CyD complexes in water.
\end{abstract}

Chirality control by supramolecular assemblies and helical polymers based on chiral templates has attracted much attention in recent years. ${ }^{1}$ Especially guest-induced chirality control is expected to apply for the development of versatile chiral switching and sensing systems. ${ }^{2}$ To obtain the supramolecular chirality function, cyclodextrins (CyDs) are quite attractive host molecules. ${ }^{3}$ Optically inert CyDs have a chiral nature in their cavities and can be efficiently combined with various achiral chromoionophores and fluoroionophores to induce chiral nature by forming an inclusion complex with CyDs. ${ }^{4}$ In the previous study, we have reported a ditopic azoprobe (15C5-Azo-2-dpa) bearing benzo-15-crown-5 (B15C5) and dipicolylamine (dpa) as recognition sites. 15C5-Azo-2-dpa was found to form a 2:1 complex with $\gamma$-CyD and show a unique response function based on guest-induced supramolecular chirality in water. ${ }^{5}$ By allowing ditopic azoprobes to be incorporated into $\gamma$-CyD, we revealed the response behavior of the supramolecular (15C5-Azo-2-dpa) $)_{2}-\gamma$ $\mathrm{CyD}$ complex in the presence of each cationic and anionic species by measuring induced circular dichroism (ICD) spectra and UV-visible (Vis) absorption spectra. We confirmed that only when $\mathrm{K}^{+}, \mathrm{Zn}^{2+}$, and $\mathrm{CO}_{3}{ }^{2-}$ were all present, a large split-type Cotton effect appeared in the measured ICD spectra and a significant short-wavelength shift took place in the measured UV-Vis spectra. The result clearly demonstrates that the (15C5-Azo-2-dpa) $)_{2}-\gamma$-CyD complex can exhibit supramolecular chirality due to the twisted

\footnotetext{
${ }^{a}$ Department of Current Legal Studies, Faculty of Law, Meiji Gakuin University, 1518 Kamikurata-cho, Totsuka-ku, Yokohama, Kanagawa 244-8539, Japan

${ }^{b}$ Department of Materials and Life Sciences, Faculty of Science and Technology, Sophia University, 7-1 Kioi-cho, Chiyoda-ku, Tokyo 102-8554, Japan.

E-mail: ta-hayas@sophia.ac.jp

$\dagger$ Electronic supplementary information (ESI) available. See DOI: 10.1039/ c8cc02242a
}

structure of the azoprobe dimer inside the $\gamma$-CyD cavity, only when it recognizes $\mathrm{K}^{+}$and $\mathrm{Zn}^{2+}$ in the presence of $\mathrm{CO}_{3}{ }^{2-} .{ }^{5}$ From the ICD spectral change, we can estimate the spatial changes of the azoprobe dimer inside $\gamma$-CyD, which induce a change in the UV-Vis spectra. ${ }^{6}$ Therefore each guest ion can be selectively detected in the presence of the other guest ions by measuring the spectral changes.

Herein we report how the 15C5-Azo-n-dpa structure affects the selectivity of guest-induced supramolecular chirality. The dramatic selectivity changes of supramolecular chirality were found to be noted for (15C5-Azo- $\boldsymbol{n}$-dpa $)_{2}-\boldsymbol{\gamma}$-CyD complexes by controlling the spacer length of 15C5-Azo-n-dpa from ethylene $(n=2)$ to propylene $(n=3)$ to butylene $(n=4)$ units (Fig. 1$)$. Also, while 15C5-Azo- $\boldsymbol{n}$-dpa has a dpa binding site for heavy metal ions, the selectivity of guest-induced supramolecular chirality changed from $\mathrm{Zn}^{2+}$ for the (15C5-Azo-2-dpa) ${ }_{2}-\gamma$-CyD complex to

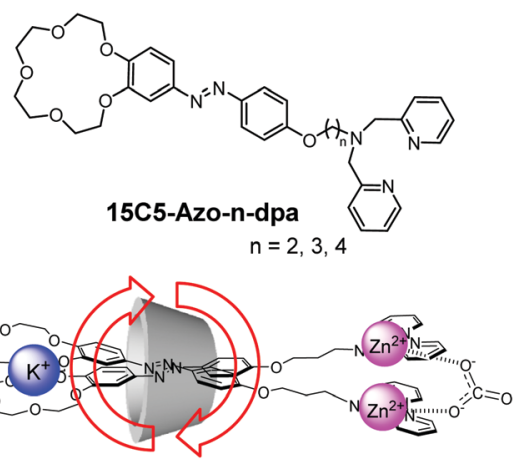

Clockwise twisted structure

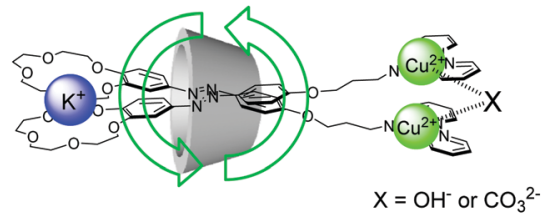

Anti-clockwise twisted structure

Fig. 1 Structure of 15C5-Azo-n-dpa and the twisted structures. 
$\mathrm{Cu}^{2+}$ for the (15C5-Azo-4-dpa) $)_{2}-\gamma$-CyD complex. However, most dpa-based chemosensors display $\mathrm{Zn}^{2+}$ and/or $\mathrm{Cd}^{2+}$ selectivity in water. ${ }^{7}$ Thus this is a unique example where the dpa-based supramolecular sensor exhibits a selectivity change from $\mathrm{Zn}^{2+}$ to $\mathrm{Cu}^{2+}$ caused by a change in the spacer length. We also report the specific selectivity changes of guest-induced supramolecular chirality for alkali-metal cations and anions based on the change in the spacer length of (15C5-Azo- $\boldsymbol{n}$-dpa $)_{2}-\boldsymbol{\gamma}$-CyD complexes in water.

The synthesis of 15C5-Azo- $\boldsymbol{n}$-dpa was carried out by the azocoupling of 4 -aminobenzo-15-crown-5 with phenol, followed by the introduction of bromoethylene, bromopropylene, and bromobutylene spacers using the Williamson ether synthesis. ${ }^{8}$ Then a dpa moiety was introduced under basic conditions with $\mathrm{K}_{2} \mathrm{CO}_{3}$, and the obtained products were purified using silica gel column chromatography. The structures of 15C5-Azo-n-dpa were confirmed via ${ }^{1} \mathrm{H}$ NMR and combustion analyses. Details of the synthesis are available in the ESI. $\dagger$

Job's plot analyses clearly revealed that 15C5-Azo- $\boldsymbol{n}$-dpa formed a $2: 1$ inclusion complex with $\gamma$-CyD in 4\% DMSO-96\% water (v/v) (Fig. S6, ESI $\dagger$ ). The ICD spectra of (15C5-Azo-n-dpa) $)_{2}^{-}$ $\gamma$-CyD complexes are depicted in Fig. 2. For 15C5-Azo-2-dpa (Fig. 2a), the selective ICD response was only noted for $\mathrm{Zn}^{2+}$ over other metal ions $\left(\mathrm{Mg}^{2+}, \mathrm{Fe}^{3+}, \mathrm{Ni}^{2+}, \mathrm{Cu}^{2+}, \mathrm{Cd}^{2+}\right.$, and $\mathrm{Pb}^{2+}$, as nitrate salts) in the presence of $50 \mathrm{mM} \mathrm{K}_{2} \mathrm{CO}_{3}$. The split ICD from the negative peak at $351 \mathrm{~nm}$ to the positive peak at $394 \mathrm{~nm}$ indicates the clockwise twisted structure of the two azoprobes inside the $\gamma$-CyD cavity. ${ }^{6}$ For 15C5-Azo-3-dpa, however, the ICD response was found to be observed not only for $\mathrm{Zn}^{2+}$ but also for $\mathrm{Cu}^{2+}$ in the presence of $50 \mathrm{mM} \mathrm{K}_{2} \mathrm{CO}_{3}$. Interestingly the ICD peak shape for $\mathrm{Cu}^{2+}$ was opposite compared with that for $\mathrm{Zn}^{2+}$, indicating that the $\mathrm{Cu}^{2+}$ complex formed an anti-clockwise twisted structure inside the $\gamma$-CyD cavity. This change in the twisted structure may be due to the difference in the coordination configuration; $\mathrm{Cu}^{2+}$ was capable of forming a coordination bond with the phenoxy ether oxygen in the dpa complexes, ${ }^{9}$ whereas only a few coordination bonds with the phenoxy ether oxygen were noted for the $\mathrm{Zn}^{2+}$-dpa complexes. ${ }^{10}$ For 15C5-Azo-4-dpa, the selective ICD response was only noted for $\mathrm{Cu}^{2+}$ over other metal ions $\left(\mathrm{Mg}^{2+}, \mathrm{Fe}^{3+}, \mathrm{Ni}^{2+}, \mathrm{Zn}^{2+}, \mathrm{Cd}^{2+}\right.$, and $\mathrm{Pb}^{2+}$, as nitrate salts $)$ in the presence of $50 \mathrm{mM} \mathrm{K} \mathrm{CO}_{3}$. Although 15C5-Azo- $\boldsymbol{n}$-dpa possesses the same dpa binding site for heavy metal ions, the selectivity was dramatically changed from $\mathrm{Zn}^{2+}$ for the (15C5-Azo-2-dpa) $)_{2}-\gamma$-CyD complex to $\mathrm{Cu}^{2+}$ for the (15C5-Azo-4-dpa) $)_{2}-\gamma-\mathrm{CyD}$ complex in the presence of $\mathrm{K}_{2} \mathrm{CO}_{3}$. The (15C5-Azo-3-dpa) $)_{2}-\gamma$-CyD complex exhibited selectivity for both $\mathrm{Zn}^{2+}$ and $\mathrm{Cu}^{2+}$, indicating an intermediate selectivity between 15C5-Azo-2-dpa and 15C5-Azo-4-dpa. ${ }^{11}$ It is evident that the spacer length of 15C5-Azo-n-dpa played an important role in controlling the selectivity of guest-induced supramolecular chirality. As shown in Fig. 2, it should be noted that the shapes of split Cotton effects based on $\pi-\pi^{*}$ transition are not symmetric, indicating the overlap of the Cotton effect based on $n-\pi^{*}$ transition at the longer wavelength. In addition, the location of azobenzenes along the $z$-axis of CyD is known to strongly affect the sign and intensity of the Cotton effect. ${ }^{6}$ Although we consider that the bulky and hydrophobic B15C5 moieties restrict the movement of azobenzenes along the

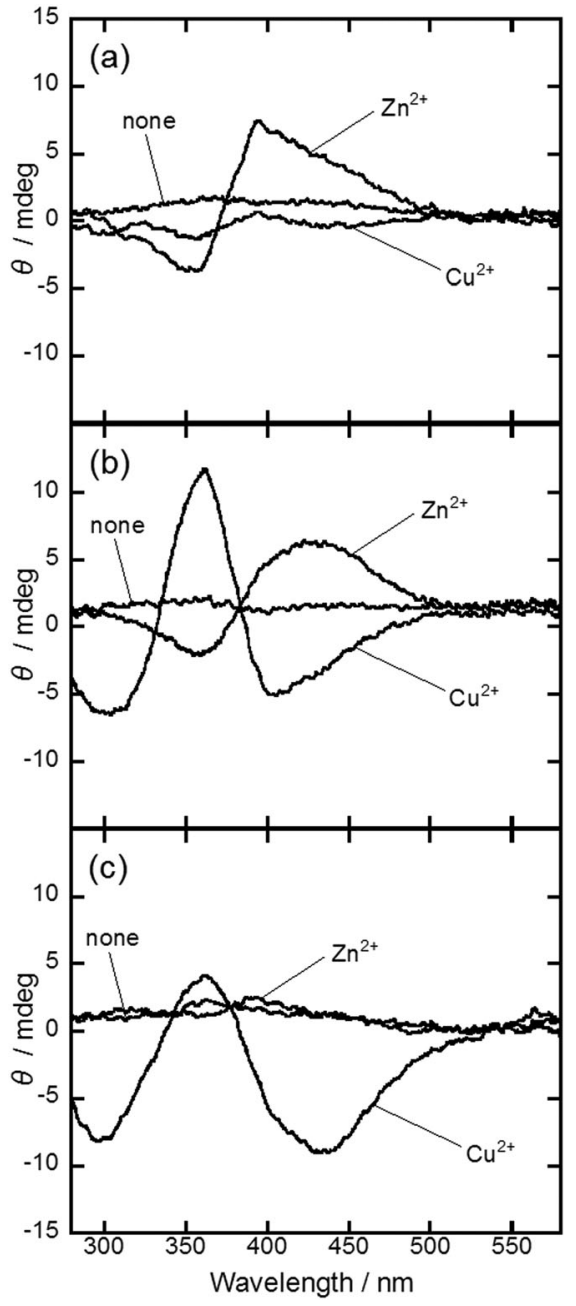

Fig. 2 ICD spectra of 15C5-Azo- $\boldsymbol{n}$-dpa/ $\boldsymbol{\gamma}$-CyD sensors in $4 \%$ DMSO aq.: (a) [15C5-Azo-2-dpa]; (b) [15C5-Azo-3-dpa]; (c) [15C5-Azo-4-dpa] = $0.04 \mathrm{mM},\left[\mathrm{Zn}\left(\mathrm{NO}_{3}\right)_{2}\right]=0.04 \mathrm{mM},\left[\mathrm{Cu}\left(\mathrm{NO}_{3}\right)_{2}\right]=0.04 \mathrm{mM},[\gamma-\mathrm{CyD}]=$ $5 \mathrm{mM},\left[\mathrm{K}_{2} \mathrm{CO}_{3}\right]=50 \mathrm{mM}$.

$z$-axis of the $\gamma$-CyD cavity, the abovementioned factors make the detailed understanding of guest-induced ICD responses difficult. To obtain further evidence for the guest-induced ICD responses, additional analysis based on molecular mechanics and TD-DFT calculations as well as X-ray crystallography analysis are to be conducted.

In the presence of equivalent amounts of $\mathrm{Zn}^{2+}$ with 15C5Azo-n-dpa $(20 \mu \mathrm{M})$, and $50 \mathrm{mM} \mathrm{CO}_{3}{ }^{2-}$, the ICD intensities at the maximum wavelength are plotted against the alkali metal ion diameter (Fig. 3a). As we reported previously, the (15C5-Azo-2dpa) ${ }_{2}-\gamma$-CyD complex exhibited high $\mathrm{K}^{+}$ion selectivity over other alkali metal ions in the presence of $\mathrm{Zn}^{2+}$ and $\mathrm{CO}_{3}{ }^{2-}$. This selectivity is consistent with the selectivity of sandwich complex formation of the two benzo-15-crown-5 derivatives with alkali metal ions. ${ }^{8,12}$ However, for the (15C5-Azo-3-dpa) ${ }_{2}-$ $\gamma$-CyD complex, the alkali metal ion selectivity was significantly reduced (Fig. 3a). This indicates that the formation of the clockwise twisted structure is dominated only by the bridge formation of $\mathrm{CO}_{3}{ }^{2-}$ with the two dpa- $\mathrm{Zn}^{2+}$ complexes in the 


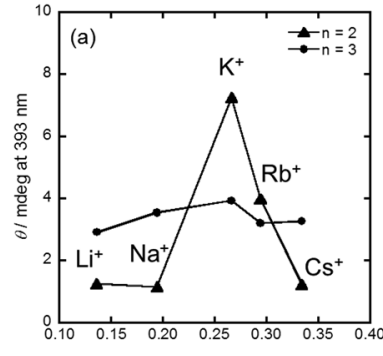

Alkali Metal lon Diameter / $\mathrm{nm}$

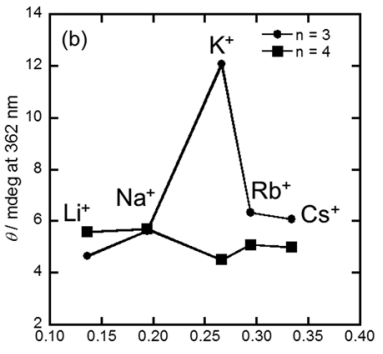

Alkali Metal Ion Diameter / nm
Fig. 3 Selectivity of 15C5-Azo- $\boldsymbol{n}$-dpa/ $\gamma$-CyD sensors toward alkali metal ions in 4\% DMSO aq., [ $\gamma$-CyD] $=5 \mathrm{mM}$, [alkali metal ion] $=50 \mathrm{mM}$ : (a) [15C5Azo-2-dpa], [15C5-Azo-3-dpa $]=0.04 \mathrm{mM},\left[\mathrm{Zn}\left(\mathrm{NO}_{3}\right)_{2}\right]=0.04 \mathrm{mM}$; (b) [15C5-Azo-3dpa], [15C5-Azo-4-dpa] $=0.04 \mathrm{mM},\left[\mathrm{Cu}\left(\mathrm{NO}_{3}\right)_{2}\right]=0.04 \mathrm{mM}$.

(15C5-Azo-3-dpa $)_{2}-\gamma$-CyD complex. The enhanced flexibility of 15C5-Azo-n-dpa upon changing the spacer from ethylene $(n=2)$ to propylene $(n=3)$ should be the reason of this selectivity change. On the other hand, in the presence of equivalent amounts of $\mathrm{Cu}^{2+}$ with 15C5-Azo-n-dpa $(20 \mu \mathrm{M})$, and $50 \mathrm{mM} \mathrm{CO}_{3}{ }^{2-}$, the (15C5-Azo-3-dpa) $)_{2}^{-}$ $\gamma$-CyD complex exhibited high $\mathrm{K}^{+}$ion selectivity similar to the $\mathrm{Zn}^{2+}$ system of the (15C5-Azo-2-dpa) $)_{2}-\gamma$-CyD complex (Fig. 3b). However, for the (15C5-Azo-4-dpa $)_{2}-\gamma$-CyD complex, no alkali metal ion selectivity was observed in the anti-clockwise twisted structure of the two azoprobes inside the $\gamma$-CyD cavity (Fig. 3b). This is also ascribed to the enhanced flexibility of 15C5-Azo- $\boldsymbol{n}$-dpa upon changing the spacer from propylene $(n=3)$ to butylene $(n=4)$.

The effect of anion species on the ICD responses was also examined for (15C5-Azo-n-dpa $)_{2}-\gamma$-CyD complexes. For the $\mathrm{Zn}^{2+}$ complex system of (15C5-Azo- $\boldsymbol{n}$-dpa $)_{2}-\gamma$-CyD complexes $(n=2,3)$, the effects of salt species on ICD responses were examined in the presence of $50 \mathrm{mM} \mathrm{KX}\left(\mathrm{X}=\mathrm{NO}_{3}{ }^{-}, \mathrm{CH}_{3} \mathrm{CO}_{2}{ }^{-}\right.$, and $\left.\mathrm{OH}^{-}\right)$. The results are depicted in Fig. 4 . Similar to the (15C5-Azo-2-dpa) $)_{2}-\gamma$ CyD complex, the (15C5-Azo-3-dpa $)_{2}-\gamma$-CyD complex exhibited high $\mathrm{CO}_{3}{ }^{2-}$ selectivity, indicating that $\mathrm{CO}_{3}{ }^{2-}$ bridging with the two $\mathrm{Zn}^{2+}$-dpa binding sites induced the clockwise twisted structure of the azoprobe dimer inside the $\gamma$-CyD cavity. In addition, direct evidence of the relative orientation of the azoprobes and the macrocyclic ring was obtained via NOESY experiments. Cross-peaks between $\mathrm{H} 3$ protons inside the CyD cavity and protons of the azoprobes were clearly observed (Fig. S7, ESI $\dagger$ ).
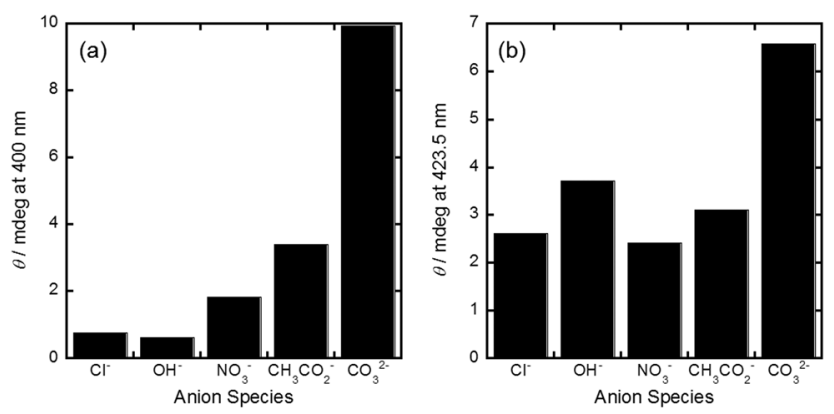

Fig. 4 Selectivity of (15C5-Azo-n-dpa- $\left.\mathbf{Z n}^{2+}\right)_{2}-\gamma$-CyD sensors toward anions in 4\% DMSO aq: (a) [15C5-Azo-2-dpa] =0.04 mM; (b) [15C5Azo-3-dpa $]=0.04 \mathrm{mM},\left[\mathrm{Zn}\left(\mathrm{NO}_{3}\right)_{2}\right]=0.04 \mathrm{mM},[\gamma-\mathrm{CyD}]=5 \mathrm{mM},\left[\mathrm{Cl}^{-}\right]$, $\left[\mathrm{OH}^{-}\right],\left[\mathrm{NO}_{3}^{-}\right],\left[\mathrm{CH}_{3} \mathrm{CO}_{2}^{-}\right],\left[\mathrm{CO}_{3}^{2-}\right]=50 \mathrm{mM}$.
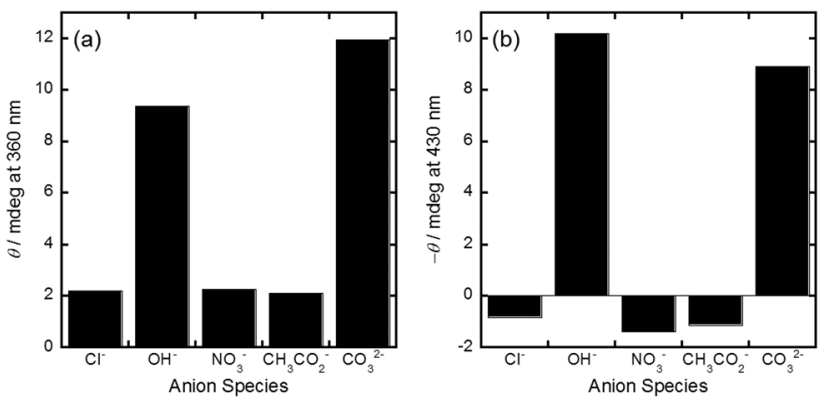

Fig. 5 Selectivity of (15C5-Azo- $n$-dpa-Cu $\left.\mathbf{C u}^{2+}\right)_{2}-\gamma-C y D$ sensors toward anions in 4\% DMSO aq.: (a) [15C5-Azo-3-dpa] =0.04 mM; (b) [15C5-Azo-4-dpa] = $0.04 \mathrm{mM},\left[\mathrm{Cu}\left(\mathrm{NO}_{3}\right)_{2}\right]=0.04 \mathrm{mM},[\gamma-\mathrm{CyD}]=5 \mathrm{mM},\left[\mathrm{Cl}^{-}\right],\left[\mathrm{OH}^{-}\right],\left[\mathrm{NO}_{3}{ }^{-}\right]$, $\left[\mathrm{CH}_{3} \mathrm{CO}_{2}^{-}\right],\left[\mathrm{CO}_{3}^{2-}\right]=50 \mathrm{mM}$.

On the other hand, for the $\mathrm{Cu}^{2+}$ complex system of (15C5-Azo-ndpa $)_{2}-\gamma$-CyD complexes $(n=3 \text { and } 4 \text { ), the (15C5-Azo- } n \text {-dpa })_{2}-\gamma$ CyD complexes showed both $\mathrm{CO}_{3}{ }^{2-}$ and $\mathrm{OH}^{-}$selectivity (Fig. 5). This indicates that hydroxo-bridging between the two $\mathrm{Cu}^{2+}-\mathrm{dpa}$ binding sites induced the anti-clockwise twisted structure of the azoprobe dimer in the (15C5-Azo-n-dpa) $)_{2}-\gamma$-CyD complex. Thus, by changing the metal species of the dpa binding sites, the anion selectivity of the (15C5-Azo-3-dpa $)_{2}-\gamma$-CyD complex can be easily controlled from the $\mathrm{CO}_{3}{ }^{2-}$ selectivity with the $\mathrm{Zn}^{2+}$ system to both $\mathrm{CO}_{3}{ }^{2-}$ and $\mathrm{OH}^{-}$selectivity with the $\mathrm{Cu}^{2+}$ system in water. These are apparently a unique function of guest-induced supramolecular chirality based on (15C5-Azo-n-dpa $)_{2}-\gamma$-CyD complexes.

In conclusion, we have shown a novel guest-induced supramolecular chirality induced by twisted structural switching of the two 15C5-Azo-n-dpa molecules inside the $\gamma$-CyD chiral cavity due to multi-point recognition of guest ions by the ditopic azoprobes in water. Although the two recognition sites are the same, a slight change in the spacer length of 15C5-Azo-n-dpa was found to significantly affect the ICD response selectivity of (15C5-Azo- $\boldsymbol{n}$-dpa $)_{2}-\gamma$-CyD complexes. To the best of our knowledge, this is a novel selectivity control based on guestinduced supramolecular chirality which completely differs from the design strategy of conventional molecular recognition systems.

This work was supported by Grants-in-Aid for Scientific Research (A) (Grant No. JP26248038) and Scientific Research (C) (Grant No. JP15K05548) from Japan Society for the Promotion of Science (JSPS). We also thank Prof. Tony D. James (University of Bath) for his helpful advice.

\section{Conflicts of interest}

There are no conflicts to declare.

\section{Notes and references}

1 Supramolecular Chirality, in Top. Curr. Chem., ed. M. Crego-Calama and D. N. Reinhovdt, 2006, p. 26; Amplification of Chirality, in Top. Curr. Chem., ed. K. Soai, 2008, p. 284; Chirality at the Nanoscale, ed. D. B. Amabilino, Wiley-VCH, Weinheim, 2009; R. Raval, Chem. Soc. Rev., 2009, 38, 707; J. Crassovs, Chem. Soc. Rev., 2009, 38, 830; M. Liu, L. Zhang and T. Wang, Chem. Rev., 2015, 115, 7304. 
2 Z. Kokan, B. Peric, M. Vazdar, Z. Marinic, D. V. Topic, E. Mestrovic and S. I. Kirin, Chem. Commun., 2017, 53, 1945; Comprehensive Chiroptical Spectroscopy, ed. N. Berova, P. L. Polavarapu, K. Nakanishi and R. W. Woody, Wiley-VCH, New York, 2012; K. C.-F. Lrung, C.-P. Chak, C.-M. Lo, W.-Y. Wong, S. Xuan and C. H. K. Cheng, Chem. - Asian J., 2009, 4, 364; R. Klajn, J. F. Stoddart and B. A. Gtrzybowski, Chem. Soc. Rev., 2010, 39, 2203; J. W. Canary, S. Morteznei and J. Liang, Coord. Chem. Rev., 2010, 254, 2249; C. Colvccini, A. Mazzrnti and D. Pasini, Org. Biomol. Chem., 2010, 8, 1807; M. Caricato, C. Colvccini, D. Dondi, D. A. Vander Griend and D. Pasini, Org. Biomol. Chem., 2010, 8, 3272; M. Caricato, A. Olmo, C. Gargivlli, G. Gattvso and D. Pasini, Tetrahedron, 2012, 68, 7861; Y. Nakatani, Y. Furusho and E. Yashima, Org. Biomol. Chem., 2013, 11, 1614; M. Ziegler, A. V. Davis, D. W. Johnson and K. N. Raymond, Angew. Chem., Int. Ed., 2003, 42, 665; A. Mammana, A. D'Vrso, R. Lauceri and R. Pvrrello, J. Am. Chem. Soc., 2007, 129, 8062; L. Rosaria, A. D'Vrso, A. Mammana and R. Purrello, Chirality, 2008, 20, 411; I. D. Cat, Z. Gvo, S. J. George, E. W. Meijer, A. P. H. J. Schenning and S. D. Feyter, J. Am. Chem. Soc., 2012, 134, 3171; P. A. Korevaar, S. J. George, A. J. Markvoort, M. M. J. Smulders, P. A. J. Hilbers, A. P. H. J. Schenning, T. F. A. de Greef and E. W. Meijer, Nature, 2012, 481, 492; W. Zhang, W. Jin, T. Fukushima, N. Ishii and T. Aida, J. Am. Chem. Soc., 2013, 135(1), 114; M.-C. Li, N. Ousaka, H.-F. Wang, E. Yashima and R.-M. Ho, Macro Lett., 2017, 6, 980; M. Weis, C. Waloch, W. Seiche and B. Breif, J. Am. Chem. Soc., 2006, 128, 4188; J. Meevwissen and J. N. H. Reek, Nat. Chem., 2010, 2, 615; P. W. N. M. Van Leevwen, D. Rivillo, M. Ranal and Z. Frexa, J. Am. Chem. Soc., 2011, 133, 18562; M. Hatano and K. Ishihara, Chem. Commun., 2012, 48, 4273; E. Yashima, K. Maeda and Y. Okamoto, Nature, 1999, 399, 449; H. Ito, M. Ikeda, T. Hasegawa, Y. Furusho and E. Yashima, J. Am. Chem. Soc., 2011, 133, 3419; H. Yamada, Y. Furusho and E. Yashima, J. Am. Chem. Soc., 2012, 134, 7250; H. Yamada, Z. Q. Wu, Y. Furusho and E. Yashima, J. Am. Chem. Soc., 2012, 134, 9506; M. Kumar, N. Jonnalagadda and S. J. George, Chem. Commun., 2012, 48, 10948; W. Makiguchi, S. Kobayashi, Y. Furusho and E. Yashima, Angew. Chem., Int. Ed., 2013, 52, 5275; S. Yamamoto, H. Iida and E. Yashima, Angew. Chem., Int. Ed., 2013, 52, 6849.

3 G. Wenz, Angew. Chem., Int. Ed. Engl., 1994, 33, 803.
4 U. Klein, G. Gimpl and F. Fahrenholz, Biochemistry, 1995, 34, 13784; L. Szente and J. Szeman, Anal. Chem., 2013, 85, 8024; T. Kida, T. Iwamoto, H. Asahara, T. Hinoue and M. Akashi, J. Am. Chem. Soc., 2013, 135, 3371; C. Shimpuku, R. Ozawa, A. Sasaki, F. Sato, T. Hashimoto, A. Yamauchi, I. Suzuki and T. Hayashita, Chem. Commun., 2009, 1709.

5 K. Nonaka, M. Yamaguchi, M. Yasui, S. Fujiwara, T. Hashimoto and T. Hayashita, Chem. Commun., 2014, 50, 10059.

6 B. Mayer, X. Zhang, W. M. Nau and G. Marconi, J. Am. Chem. Soc., 2001, 123, 5240; M. Kodaka and T. Furuya, Bull. Chem. Soc. Jpn., 1989, 62, 1154; M. Kodaka, J. Am. Chem. Soc., 1993, 115, 3702; M. Kodaka, J. Phys. Chem., 1991, 95, 2110; K. Harata and H. Uedaira, Bull. Chem. Soc. Jpn., 1975, 48, 375; I. Tinoco, Jr., Adv. Chem. Phys., 1962, 4, 113.

7 K. Ghosh, D. Tarafdar, A. Majumdar, C. G. Daniliuc, A. Samadder and A. R. Khuda-Bukhsh, RSC Adv., 2016, 6, 47802; S. Sumiya, Y. Shiraishi and T. Hirai, J. Phys. Chem. A, 2013, 117, 1474; P. Das, S. Bhattacharya, S. Mishra and A. Das, Chem. Commun., 2011, 47, 8118; K. M. K. Swamy, M.-J. Kim, H.-R. Jeon, J.-Y. Jung and J. Yoon, Bull. Korean Chem. Soc., 2010, 31, 3611.

8 F. Sato, M. Tsukano, K. Sakamoto, W. Umemoto, T. Hashimoto and T. Hayashita, Bull. Chem. Soc. Jpn., 2008, 81, 1589; F. Sato, K. Sakamoto, W. Umemoto, T. Hashimoto and T. Hayashita, Chem. Lett., 2007, 36(7), 880.

9 Y. Mikata, T. Fujimoto, T. Fujiwara and S. Kondo, Inorg. Chim. Acta, 2011, 370, 420; Đ. Škalamera, E. Sanders, R. Vianello, A. Maršavelski, A. Pevec, I. Turel and S. I. Kirin, Dalton Trans., 2016, 45, 2845; E. Y. Tirel, Z. Bellamy, H. Adams, V. Lebrun, F. Duarte and N. H. Williams, Angew. Chem., Int. Ed., 2014, 53, 8246.

10 B. Mayer, X. Zhang, W. M. Nau and G. Marconi, J. Am. Chem. Soc., 2001, 123, 5240; M. Kodaka, J. Am. Chem. Soc., 1993, 115, 3702; M. Kodaka, J. Phys. Chem., 1991, 95, 2110; K. Harata and H. Uedaira, Bull. Chem. Soc. Jpn., 1975, 48, 375; I. Tinoco, Jr., Adv. Chem. Phys., 1962, 4, 113.

11 To elucidate the metal ion selectivity, the effects of metal ion concentration on ICD responses are depicted in Fig. S4, ESI $\dagger$.

12 A. Yamauchi, T. Hayashita, A. Kato, S. Nishizawa, M. Watanabe and N. Teramae, Anal. Chem., 2000, 72, 5841; A. Yamauchi, T. Hayashita, S. Nishizawa, M. Watanabe and N. Teramae, J. Am. Chem. Soc., 1999, 121, 2319. 